\title{
Psychometric properties of the Persian version of the Intensive and Critical Care Nursing Competence Scale version-1 (ICCN-CS-1)
}

Ali Asghar Shouryabi ${ }^{1}$, Alireza Ghahrisarabi ${ }^{2}$, Sima Zohari Anboohi ${ }^{3}$, Malihe Nasiri ${ }^{4}$, Maryam Rassouli $^{5}$

${ }^{1}$ M.Sc. of Critical Care Nursing, Nursing and Midwifery College, Shahid Beheshti University of Medical Sciences, Tehran, Iran

${ }^{2}$ M.Sc. of Nursing, Instructor, Department of Anesthesia \& Operating Room, Faculty of Nursing and Midwifery, Nursing and Midwifery College, Shahid Beheshti University of Medical Sciences, Tehran, Iran

${ }^{3}$ Ph.D. of Nursing, Assistant Professor, Faculty of Nursing and Midwifery, Nursing and Midwifery College, Shahid Beheshti University of Medical Sciences, Tehran, Iran

${ }^{4}$ Ph.D. of Biostatistics, Department of Biostatistics, Nursing and Midwifery College, Shahid Beheshti University of Medical Sciences, Tehran, Iran

${ }^{5}$ Ph.D. of Nursing, Associate Professor, Faculty of Nursing and Midwifery, Nursing and Midwifery College, Shahid Beheshti University of Medical Sciences, Tehran, Iran

Type of article: Original

\begin{abstract}
Background: Nursing competence is highly related to patient outcomes and patient safety issues, especially in intensive care units. Competence assessment tools are needed specifically for intensive care nursing.

Objective: This study was performed to determine psychometric properties of the Intensive and Critical Care Nursing Competence Scale version-1 between Iranian Nurses.

Methods: The present study was a methodological research in which 289 nurses of Intensive Care Units from nine hospitals in Shahid Beheshti University of Medical Sciences in Tehran were selected between 2015 and 2016. The original version of the scale was translated into Persian and back-translated into English, and the comments of the developer were applied. The validity of the scale was the determined quality (content validity and face validity) and quantity (confirmatory factor analysis). Reliability of the scale was reported by Cronbach's alpha coefficient and Intra class Correlation Coefficient. SPSS-PC (v.21) and LISREL (v.8.5) were used to analyze the data.

Results: The intensive and critical care nursing competence scale version-1 is a self-assessment test that consists of 144 items and four domains which are the knowledge base, the skill base, the attitudes and values base and the experience base, which are divided into clinical competence and professional competence. Content and face validity was confirmed by 10 experts and 10 practitioner nurses in the intensive care units. In confirmatory factor analysis, all fitness indexes, except goodness of fit index (0.64), confirmed the four-factor structure of the ICCNCS-1. The results of the factor analysis, load factor between 0.304 and 0.727 items was estimated; only 4 items out of 144 items, that were loaded were less than 0.3 due to high Cronbach's alpha coefficient (0.984-0.986), all items were preserved, no item was removed and 4 subscales of the original scale were confirmed.

Conclusion: The results of this study indicated that the Persian version of "The Intensive and Critical Care Nursing Competence Scale version-1" is a valid and reliable scale for the assessment of competency among Iranian nurses, and it can be used as a reliable scale in nursing management, education and research.

Keywords: Psychometric, Competence, Scale, Intensive care nursing, Critical Care nursing
\end{abstract}

\section{Introduction}

Intensive and critical care nursing is focused on the treatment of severely ill patients. These patients benefit from the attention of highly trained and skilled personnel applying modern techniques and interventions appropriately,

\section{Corresponding author:}

Alireza Ghahrisarabi, Shahid Beheshti University of Medical Sciences, Tehran, Iran.

Tel: +98.2188202535, Email: ARGS1340@gmail.com

Received: August 15, 2016, Accepted: June 01, 2017, Published: November 2017

iThenticate screening: May 17, 2017, English editing: September 09, 2017, Quality control: October 10, 2017

(C) 2017 The Authors. This is an open access article under the terms of the Creative Commons Attribution-NonCommercialNoDerivs License, which permits use and distribution in any medium, provided the original work is properly cited, the use is non-commercial and no modifications or adaptations are made. 
intelligently and compassionately (1). Nurses, which are the largest group of service providers in health systems (2) are the largest professional group in ICUs (3). Clinical competency is very important for patient care in the complex environments of intensive care units (4). Nowadays, in the competitive world, it is a key factor in the survival of hospitals (5). Competence in nursing has strong relations with patient outcomes and patient safety, quality of care, patients' satisfaction (6), reduction in medical errors, nosocomial infections, mortality, postoperative complications, and unplanned extubation, especially in intensive care units (3). Nurses are encouraged to increase their level skills, critical thinking, and self-learning by determining their level of competence (7). Reduction in clinical competence level may lead to duplication in care, which results in energy wastage, cost and time, patients dissatisfaction from unfavorable care by nurses, vast work faults, putting patients and the health of personnel at risk, reduction in efficiency, ineffective use of personnel ability, a lot of unfinished activity at the end of work shifts, fatigue, and nurses left feeling that the number of personnel is inadequate (8). Lack of competence in intensive care units could lead to an increase in, for example, the number of patients falling out of bed, medical errors, and reduction in the safety and health of patients (9). From 1999 to date, the issue of nurses' clinical competence evaluating has been considered as a principal subject in this field (10). In 2000, the World Health Organization emphasized the importance of nurses' professional competence to ensure quality nursing care $(11,12)$. Competency is the quality or state of the proportional existence of an activity, which is hard to be studied. It has also been described as a specific trait used to judge a person's adequacy or capability. Competence is the reflection of knowledge, critical thinking, and individual and technical skills exhibited by people in professional clinical situations (7). The use of valid and reliable tools is very important in different areas of this concept. However, there are shortages in such tools (13). There is little evidence for systematically organized competency assessment. Validity and reliability of measurement tools or strategies were rarely reported (14). In summary, a lot of competence measuring tools do not have concrete evidence of validity, reliability, or both (15) and the present tools have rarely tested validity and reliability (16). Few of them have been tested for psychometric properties (17). Development of competence assessment tools are needed specifically for intensive care nursing. Intensive care nursing is a unique and special type of nursing that cannot be assessed with a general nursing competence tool. There is no tested reliable and valid basic competence assessment scale for intensive and critical care nursing (3). Several instruments have been used in development and psychometrics in different countries for nursing competency assessment, which can be named between them as follows: Nurse Competence Scale (18), The Competency Inventory for Registered Nurses (CIRN) (12), The EHTAN questionnaire tool (EQT)-The European Health Care Training and Accreditation Network (EHTAN) (19), The Australian Nursing Competency Incorporated (ANCI) 2000 standards (20), Australian Nursing Competency Incorporated (ANCI) 2000 standards (21), The Holistic Nursing Competence Scale (HNCS) (16), Nurse Professional Competence (NPC) (17), The Clinical Competence Questionnaire (CCQ) (15), Competency Inventory for Postgraduate Students of Intensive Care Nursing (22), and The Professional Nurse Self-Assessment Scale (23). However, these tools, are not exclusive to the assessment of intensive care nursing competence. Some of these tools assess clinical competency and others evaluate professional competency. The three existing tools of intensive care nursing (24-26) measure competence in that field only partly. Two of them are basic biological-physiological knowledge tests $(24,26)$, while the competence standards tool 2005 by Fisher et al. assesses special-level nursing. The Intensive and Critical Care Nursing Competence Scale version-1 was developed with psychometric testing by Lakanmaa et al. (3) for basic competence assessment in intensive and critical care nursing. This scale can be used both for assessment of basic competence of nurses working in clinical practice and for measuring basic competence in nursing education in this special field.

The scale is useful in newcomers' orientation programs while developing, for example, the content of the program and supervision. The scale is a self-assessment test consisting of 144 items over four individual domains: a knowledge base, a skill base, an attitudes and values base, and an experience base. Each domain contains 36 items. Each item is on a 5 -point Likert score, with $1=$ very poor and $5=$ very good score. Scores on the scale can be classified as poor competence $(=1,144-288$, Likert $1-2 \times 144)$, moderate competence $(=2,289-432$, Likert $2-3 \times$ $144)$, good competence $(=3,433-567$, Likert 3-4 × 144) or excellent competence $(=4,577-720$, Likert 4-5 $\times 144)$. Basic competence is divided into patient-related clinical competence and general professional competence. The ICCN-CS-1 can be used both by graduating nursing students and ICU nurses for self-assessment of competence (3). The survey of two clinical and professional competence dimensions is one of the points of strength of the ICCN-CS1 , which evaluates the areas of knowledge base, skill base, attitudes and values base, and experience base. This scale has not yet been used for psychometrics in any country. To date, the special tool has not been introduced on competence level measurement of Iranian nurses in intensive care units. The purpose of this study is to determine the psychometric properties of Persian Version of "the Intensive and Critical Care Nursing Scale Version-1". 


\section{Material and Methods}

\subsection{Research design and setting}

The present study was a methodological research (27), in which the Persian version of ICCN-CS-1 was translated and validated among Iranian nurses. The study population were nurses of intensive care units from nine hospitals in Shahid Beheshti University of Medical Sciences in Tehran, from March 2015 through February 2016. Simple random sampling method was performed in order to achieve a sufficient sample size to conduct a confirmatory factor analysis. The inclusion criteria were having at least a bachelor's degree in nursing, practitioner nurses of intensive care units in hospitals affiliated to Shahid Beheshti University of Medical Sciences and willingness to participate in research. The exclusion criterion was non-completion of responses to items of ICCN-CS-1. Based on these criteria, 450 nurses were eventually chosen.

\subsection{Scale translation}

We translated and validated the intensive and critical care nursing competence scale version -1 according to the method suggested by Wild et al. (28). After electronic communication and approval by the original developer of the scale, it was translated into Persian by two translators whose native language was Persian and had enough experience and mastery of English texts translation into Persian, who were selected according to the purposive method. Efforts were made to ensure that the translation did not change the meaning and concept even at a difficult level of translation. To this end, the equivalent of the terms, phrases and sentences were affirmed. The two translations were compared and edited by five faculties of the School of Nursing and Midwifery of Shahid Beheshti University of Medical Sciences and a final copy was prepared. Early translators were not involved at this stage. In the next step, the text was back-translated into English by one qualified translator in Persian and English (an English language expert) and sent to the designers of the scale by e-mail for the same concept and final confirmation of the Persian version and the original English version that she agreed to provide in English. At this stage, the scale developer's verification was received. Afterward, the comments of the designers were applied by the research team and the Persian version of the intensive and critical care nursing competence scale was confirmed, and the validation process of the translated scale was conducted by assessing content and face validity, construct validity (by confirmatory factor analysis), reliability, and internal consistency.

\subsection{Content validity}

The CVI is an index of inter-rater agreement (29). Proportion agreement lacks a value indicating "no agreement," thereby creating the potential for inflation of agreement due to chance (30). One concern that has been raised about the CVI is that it is an index of interpreter agreement that simply expresses the proportion of agreement, and agreement can be inflated by chance factors (31). Face and content validity were performed qualitatively. The translated scale (paper) was given to ten experts (faculties of the School of Nursing and Midwifery of Shahid Beheshti University of Medical Sciences) and ten practitioner nurses in various intensive care units (in hospitals) to review it and provide their comments. They were also asked to express their ideas about grammar using the right words, clarity, simplicity and comprehension of words and phrases. They also confirmed the face validity of the Persian version of the ICCN-CS-1.

\subsection{Construct validity}

To factor analyze, Burns and Grove suggested 5 to 10 samples per variable (32). On average, three samples per variable are sufficient. The number of samples required for factor analysis is different to aid the determination of the construct validity of researchers. Whereas factor analysis is performed based on correlation, 100-200 samples will suffice for this purpose. However, there is no clear law for the number of samples (33). At this stage, convenient sampling was performed. In consonance with the law of the construct validity, and number of items of ICCN-CS-1 (144 items), a minimum of 432 cases were estimated and ultimately, 450 cases were considered. In this study, indices of fit, the ratio of chi square to degree of freedom, goodness of fit index (GFI), comparative fit index (CFI), incremental fit index (IFI), normed fit index (NFI), non-normed fit index or Tucker Lewis index (NNFI or TLI), root mean square residual approximately (RMSRA) and root mean square error of approximation (RMSEA) were evaluated.

\subsection{Reliability}

Internal consistency reliability of the scale was calculated by Cronbach's alpha. The correlation between test-retest among 32 practitioner nurses in intensive care units in different hospitals who had participated in a previous stage within the time interval of two weeks, were selected by simple random method. LISREL 8.5 was used for 
http://www.ephysician.ir

confirmatory factor analysis of all four dimensions of the ICCN-CS-1. Internal consistency reliability and test-retest were performed by using SPSS version 21 .

\subsection{Ethical Considerations}

Approval by the original developer of the scale was given by electronic communication. We gained approval for the study from the ethical committee of Shahid Beheshti University of Medical Sciences (ethical approval code: SBMU2.REC.1394.169), Tehran, Iran. Informed consent was obtained from all participants prior to filling in the scale. Objectives of the study were explained and researchers promised to keep the participants' information confidential.

\section{Results}

\subsection{Demographic characteristics}

The total samples were 432 practitioner nurses in intensive care units of which 143 participants did not complete the scale and 289 (67\%) participants completed the scale. Most of the participants were female $(88.4 \%, n=244)$ and $16.6 \%$ were male $(n=45)$, the participants mean age was 35.93 years old with SD $=7.382($ range $23-59)$ and they had 1-30 years' work experience in nursing $($ mean $=11.29, \mathrm{SD}=6.765)$, also, they had 1-26 years' work experience in the intensive care nursing (mean $=7.61, \mathrm{SD}=5.592$ ). Overtime average worked per month was 0-120 hours (mean $=49.11, \mathrm{SD}=12.259)$. The demographic characteristics of the nurses are reported in Table 1 .

Table 1. Demographic characteristics of the practitioner nurses

\begin{tabular}{|c|c|c|c|}
\hline Parameter & Category & $\mathrm{n}$ & $\%$ \\
\hline \multirow[t]{2}{*}{ Sex } & Female & 244 & 84.4 \\
\hline & Male & 45 & 16.6 \\
\hline \multirow[t]{4}{*}{ Age (years) } & $22-30$ & 83 & 28.7 \\
\hline & $31-38$ & 99 & 34.3 \\
\hline & $39-46$ & 82 & 28.4 \\
\hline & $>47$ & 25 & 8.6 \\
\hline \multirow[t]{3}{*}{ Marital status } & Single & 93 & 32.17 \\
\hline & Married & 192 & 66.43 \\
\hline & Widowed or divorced & 4 & 1.37 \\
\hline \multirow[t]{6}{*}{ Work experience in nursing (years) } & $1-5$ & 71 & 24.56 \\
\hline & $6-10$ & 73 & 25.25 \\
\hline & $11-15$ & 57 & 19.7 \\
\hline & $16-20$ & 63 & 21.8 \\
\hline & $21-25$ & 16 & 5.53 \\
\hline & $>26$ & 9 & 3.11 \\
\hline \multirow[t]{6}{*}{ Work experience in intensive care nursing (years) } & $1-5$ & 136 & 47 \\
\hline & $6-10$ & 66 & 22.83 \\
\hline & $11-15$ & 56 & 19.37 \\
\hline & $16-20$ & 29 & 10 \\
\hline & $21-25$ & 1 & 0.34 \\
\hline & $>26$ & 1 & 0.34 \\
\hline \multirow[t]{3}{*}{ Education level } & Graduate & 257 & 89 \\
\hline & post Graduate & 32 & 11 \\
\hline & $\mathrm{PhD}$ & 0 & 0 \\
\hline \multirow[t]{3}{*}{ Work shift } & Morning & 37 & 12.8 \\
\hline & Evening & 1 & 0.34 \\
\hline & Rotation & 251 & 86.9 \\
\hline \multirow[t]{6}{*}{ Overtime average worked per month (hours) } & $<20$ & 1 & 0.34 \\
\hline & $20-40$ & 51 & 17.7 \\
\hline & $41-60$ & 216 & 74.4 \\
\hline & $61-80$ & 14 & 4.8 \\
\hline & $81-100$ & 6 & 2 \\
\hline & $>100$ & 1 & 0.34 \\
\hline
\end{tabular}




\subsection{Translation of Persian Version Scale}

We translated and validated the intensive and critical care nursing competence scale version 1 . The scale was studied by 10 practitioner nurses in intensive care units for basic information on wording and vague points, and their comments were utilized by the research team. The only vague point mentioned by the nurses was item number 4 , which was changed from "same (identical) as" to" be similar to", then reforms in the scale were carried out and the final version was ready to be used in psychometrics.

\subsection{Content Validity}

A total of 10 experts (members of Shahid Beheshti Faculty of Nursing and Midwifery) and 10 nurses evaluated simultaneously all the statements of the scale in terms of "relevance, simplicity and clarity" and all the items were relevant, simple and clear. Only item number 3 for some nurses and item number 4 for some nurses and some experts were not simple and clear. By consultation with teachers and advisors and faculty members, item number 3 was changed from the "patient-centered" to "patient-centered (focus on patient)" and item number 4 from "to be similar" to "the same (identical)". Other items were adopted without change.

\subsection{Construct Validity}

Confirmatory factor analysis was used to assess the original four-dimensional ICCN-CS-1. In order to confirm the factor structure and examine the power and significant contribution of each factor, the ratio of chi square to degree of freedom was 4.36. The other fit indices such as goodness of fit index 0.64, comparative fit index 0.95, incremental fit index 0.95, normed fit index 0.95, non-normed fit index or Tucker Lewis index 0.94, root mean square residual approximately 0.031 and root mean square error of approximation was 0.10 statistically. Load factor between 0.304 and 0.727 items was estimated; only 4 items out of 144 items $(15,25,37$ and 109) that were loaded were less than 0.3. Due to high Cronbach's alpha coefficient (0.984-0.986), all items were preserved and no item was removed (Table 2). Overall, based on the mentioned indicators, it can be said that the factor analysis of "the intensive and critical care nursing competence version-1" confirmed to optimal fitness. Comparative fit index and goodness of fit index had a range of zero to one. Each index evaluated the pattern of fit in a unique way and the pattern implies the degree of closeness of one range to another. Some researchers have recommended that the comparative fit index should be used because it is higher than the goodness of fit and will be less affected by sample size (29).

Table 2. Item statistics

\begin{tabular}{|l|l|l|l|l|}
\hline Question & $\begin{array}{l}\text { Scale mean if } \\
\text { item deleted }\end{array}$ & $\begin{array}{l}\text { Scale variance if } \\
\text { item deleted }\end{array}$ & $\begin{array}{l}\text { Corrected item- total } \\
\text { correlation }\end{array}$ & $\begin{array}{l}\text { Cronbach's Alpha if } \\
\text { item deleted }\end{array}$ \\
\hline $\begin{array}{l}\text { 15. Protection from } \\
\text { vital functions }\end{array}$ & 618.08 & 4690.129 & 0.083 & 0.985 \\
\hline $\begin{array}{l}\text { 25. Make professional } \\
\text { decisions }\end{array}$ & 618.16 & 4671.891 & 0.109 & 0.985 \\
\hline $\begin{array}{l}\text { 37. Make them feel } \\
\text { secure }\end{array}$ & 618.22 & 4645.349 & 0.714 & 0.984 \\
\hline $\begin{array}{l}\text { 109. Make patient feel } \\
\text { secure }\end{array}$ & 618.16 & 4641.324 & 0.151 & 0.986 \\
\hline
\end{tabular}

\subsection{Reliability}

Cronbach's alpha coefficient for basic knowledge, skills, attitudes and values and experience were 0.93, 0.96, 0.95 and 0.96 respectively. This indicated the excellent reproducibility of the scale. Cronbach's alpha coefficient for the total scale was reported to be 0.98 . Intra-class correlation coefficient in terms of dimension for basic knowledge was 0.89 , skill 0.83 , attitudes and values 0.87 and experience 0.84 and 0.86 for the total scale.

\section{Discussion}

The aim of this study was to translate the ICCN-CS-1 into Persian and assess its psychometric properties in an Iranian intensive critical care nursing population. When an instrument of culture or language is translated into another language or used in another culture, its psychometric properties need to be evaluated (34). The intensive and critical care nursing competence scale Version-1, is not an exception. In this study, psychometric properties were assessed by face validity, content validity and, construct validity and reliability. Face validity and content validity were carried out by qualitative method; and content validity was confirmed by 10 experts who considered a few changes. A 2014 study by Lakanmaa et al. (3) showed that the scale has acceptable validity. They conducted face 
validity and content validity by qualitative method with 45 experts and content validity was $80 \%$. The results showed that face validity and content validity of "ICCN- CS-1" were acceptable and approved for quantitative analysis. The quantitative data included demographic findings, construct validity and reliability. The total samples were 450 practitioner nurses in intensive care units of which 432 participants answered the scale. A total of 143 participants did not complete the scale and 289 (67\%) participants completed the scale. In the study of Lakanmaa et al., (3) 431 practitioner nurses in intensive care units (54\% response) and 139 graduating nursing students (59\% response) participated in the development of a psychometric Finnish version of "the intensive and critical care nursing competence scale version1" (3). Convenient samples were used in both studies. Confirmatory factor analysis of "ICCN-CS-1" was conducted with 289 practitioner nurses in the intensive care units. Due to the fact that 7 of the 8 indicators for the fit index showed an acceptable score, 4-dimensional structure of the original scale was confirmed. Considering the fact that the Chi-square statistic is sensitive to sample size, Chi-square statistic relationship ( $\left.\mathrm{X}^{2} / \mathrm{df}\right)$ was used to calculate and measure the overall appropriateness of the model (35). This index was 4.36. Comparative fit index is another fit index of confirmatory factor analysis. Acceptable values for this indicator are 0.9-0.95 to express the fitness of the model (36). In this study, comparative fit index was 0.95 . Values of other fitness indicators were goodness of fit index 0.64, gradual index fitting 0.95, normed fit index 0.95 , Tucker Lewis or non-normed fit index 0.94, root mean square residual 0.031 and root mean square error of approximation 0.1 respectively. A reliable tool increased the power of the study to detect differences in meaningful communication that occurs in research (32). Reliability in a tool is one of the most important criteria that show the quality of the tool. Reliability criteria of this scale were Cronbach's alpha coefficient and the test-retest methodology, which showed acceptable internal consistency and stability of this scale. The results showed that "ICCN-CS-1" had a high stability. Cronbach's alpha coefficient for the basic knowledge, skill, attitude and value and experience was 0.93, 0.96, 0.95 and 0.96 respectively indicating an excellent repeatability of the scale. Cronbach's alpha coefficient for the total scale was reported to be 0.98 . Cronbach's alpha coefficient in the study of Lakanmaa et al. (3) was also 0.98. The Cronbach's alpha coefficient values were high and the nature of the competence scale is unidimensional, and the items correlate strongly with each other (37). Test-retest method was used in determining the consistency of the results obtained from the tests that were carried out twice, two weeks apart to show the high stability of the tool. Intra-class correlation coefficient was in the knowledge base of 0.89 , skill base 0.83 , attitude and value base 0.87 and experience base 0.84. Lakanmaa et al. (3) reported that the correlation coefficient for graduate nursing students was 0.25 to 0.81 and 0.22 to 0.70 for practitioner nurses. Several instruments for measuring and assessing nurses' clinical competence have been developed including psychometrics in different countries several years ago (12, 15, 16-23). The basic competence scale ICCN-CS-1 is a new scale and it shares the same difficulties with a previous holistic competence scale developed for critical care nursing (37).

The intensive and critical care nursing competence version -1 evaluates separately the patients' safety, justness, aseptic rules, instructions for the use of technical equipment, nurses' ethical code, organ transplantation law, and economic efficiency in four domains, which are the knowledge base, skill base, attitudes and values base and experience base. The other instrument did not expound on this case. Only Nurse Professional Competence (NPC) evaluates safety planning and nursing law. In this scale, basic competence is divided into clinical competence and professional competence. Clinical competence consists of three subdomains: principles of nursing care, clinical guidelines and nursing interventions. Professional competence consists of four subdomains: ethical activity and familiarity with health care laws, decision-making, development work, and collaboration. The scale can be used to assess the competence of graduating nursing students; therefore, the experience of scale should be removed. The scale thus consisted of 108 items, the score ranging between 108 and 540. ICCN CS-1 is useful in planning supervision in preregistration nursing students' clinical practice and during orientation programs, for example, to identify learning gaps, define learning goals, and discuss competence in a comprehensive manner. The content of the scale is in line with postgraduate education standards and the competence standards of critical care nurses, also at specialist level. The only limitations in the present study were the sampling, which exclusively covered university hospitals and the somewhat low response rate.

\section{Conclusions}

The findings of this study showed that the Persian version of the intensive and critical care nursing competence scale version-1 has acceptable psychometric properties in the Iranian nursing population and can be used as a valid scale in the areas of human resources management, promotion of nurses, their awareness of the level of competence and professional opportunities, assessment of the need for training, nursing research and education. However, we recommend further psychometric testing in other countries and the inclusion of larger samples of nurses and particularly head nurses at various intensive care units. 


\section{Acknowledgments:}

This article was part of a critical care nursing graduate thesis supported by Shahid Beheshti University of Medical Sciences (SBMU2.REC.1394.169) (Tehran, Iran). The researchers are indebted to Ms. Rita Lisa Lakanmaa (original developer of ICCN-CS-1) (3) and the nurses who participated in this study as well as all officials of the Shahid Beheshti University of Medical Sciences Hospitals.

\section{Conflict of Interest:}

There is no conflict of interest to be declared.

\section{Authors' contributions:}

All authors contributed to this project and article equally. All authors read and approved the final manuscript.

\section{References:}

1) Lakanmaa RL, Suominen T, Perttila J, Ritmala - Castrèn M, Vahlberg T, Leino - Kilpi H. Graduating nursing students' basic competence in intensive and critical care nursing. J Clin Nurs. 2014; 23(5-6): 64553. doi: 10.1111/jocn.12244. PMID: 23786502.

2) Boss LA. Teaching for clinical competence. Nurse Educ. 1985; 10(4): 8-12. PMID: 3848727.

3) Lakanmaa RL, Suominen T, Perttilä J, Ritmala - Castrén M, Vahlberg T, Leino - Kilpi H. Basic competence in intensive and critical care nursing: development and psychometric testing of a competence scale. J Clin Nurs. 2014; 23(5-6): 799-810. doi: 10.1111/jocn.12057. PMID: 23331409.

4) Elliott D, Chaboyer W. ACCCN's critical care nursing. Elsevier Australia; 2011.

5) Meretoja R, Eriksson E, Leino - Kilpi H. Indicators for competent nursing practice. J Nurs Manag. 2002; 10(2): 95-102. PMID: 11882110.

6) Ying L, Kunaviktikul W, Tonmukayakal O. Nursing competency and organizational climate as perceived by staff nurses in a Chinese university hospital. Nurs Health Sci. 2007; 9(3): 221-7. doi: 10.1111/j.14422018.2007.00324.x. PMID: 17688481.

7) Applin H, Williams B, Day R, Buro K. A comparison of competencies between problem-based learning and non-problem-based graduate nurses. Nurse Educ Today. 2011; 31(2): 129-34. doi: 10.1016/j.nedt.2010.05.003. PMID: 20817332.

8) Meretoja R, Leino - Kilpi H, Kaira AM. Comparison of nurse competence in different hospital work environments. J Nurs Manag. 2004; 12(5): 329-36. doi: 10.1111/j.1365-2834.2004.00422.x. PMID: 15315489 .

9) Wolf ZR, Miller PA, Devine M. Relationship between nurse caring and patient satisfaction in patients undergoing invasive cardiac procedures. Med Surg Nursing. 2003; 12(6): 391. PMID: 14725151.

10) Girot EA. Assessment of graduates and diplomates in practice in the UK-Are we measuring the same level of competence? J Clin Nurs. 2000; 9(3): 330-7. doi: 10.1046/j.1365-2702.2000.00393.x. PMID: 11235305.

11) Klein CJ, Fowles ER. An investigation of nursing competence and the competency outcomes performance assessment curricular approach: senior students' self-reported perceptions. J Prof Nurs. 2009; 25(2): 10921. doi: 10.1016/j.profnurs.2008.08.006. PMID: 19306834.

12) Liu M, Kunaiktikul W, Senaratana W, Tonmukayakul O, Eriksen L. Development of competency inventory for registered nurses in the People's Republic of China: scale development. Int J Nurs Stud. 2007; 44(5): 805-13. doi: 10.1016/j.ijnurstu.2006.01.010. PMID: 16519890.

13) Wangensteen S, Johansson IS, Nordstrom G. Nurse Competence Scale-Psychometric testing in a Norwegian context. Nurse education in practice. 2015; 15(1): 22-9. doi:10.1016/j.nepr.2014.11.007.

14) Yanhua C, Watson R. A review of clinical competence assessment in nursing. Nurse Educ Today. $2011 ; 31$ (8): 832-6. doi: 10.1016/j.nedt.2011.05.003. PMID: 21636181.

15) Liou SR, Cheng CY. Developing and validating the Clinical Competence Questionnaire: A self-assessment instrument for upcoming baccalaureate nursing graduates. Journal of Nursing Education and Practice. 2014; 4 (2): 56.

16) Takase M, Teraoka S. Development of the holistic nursing competence scale. Nurs Health Sci. $2011 ; 13$ (4): 396-403. doi: 10.1111/j.1442-2018.2011.00631.x. PMID: 21883769.

17) Nilsson J, Johansson E, Egmar AC, Florin J, Leksell J, Lepp M, et al. Development and validation of a new tool measuring nurses self-reported professional competence-The nurse professional competence (NPC) Scale. Nurse Educ Today. 2014; 34(4): 574-80. doi: 10.1016/j.nedt.2013.07.016. PMID: 23938092. 
18) Meretoja R, Isoaho H, Leino - Kilpi H. Nurse Competence scale: development and psychometric testing. J Adv Nurs. 2004; 47(2): 124-33. doi: 10.1111/j.1365-2648.2004.03071.x. PMID: 15196186.

19) Cowan DT, Wilson-Barnett DJ, Norman IJ, Murrells T. Measuring nursing competence: development of a self-assessment tool for general nurses across Europe. Int J Nurs Stud. 2008; 45(6): 902-13. doi: 10.1016/j.ijnurstu.2007.03.004. PMID: 17451716.

20) Andrew S, Gregory L, Cowin LS, Eagar SC, Hengstberger-Sims C, Rolley J. Psychometric properties of the Australian nurse competency 2000 standards. Int J Nurs Stud. 2008; 45(10): 1512-5. doi: 10.1016/j.ijnurstu.2007.10.008. PMID: 18243205.

21) Lin CJ, Hsu CH, Li TC, Mathers N, Huang YC. Measuring professional competency of public health nurses: development of a scale and psychometric evaluation. J Clin Nurs. 2010; $19(21$ - 22): 3161-70. doi: 10.1111/j.1365-2702.2009.03149.x. PMID: 20704628.

22) Ebadi A, Tabanejad Z, Pazokian M, Yasser S. Designing and Psychometric Evaluation of the Competency Inventory for Postgraduate Students of Intensive Care Nursing. Nurs Midwifery Stud. 2016; 5(4): e32677. doi: $10.17795 /$ nmsjournal32677.

23) Finnbakk E, Wangensteen S, Skovdahl K, Fagerström L. The Professional Nurse Self-Assessment Scale: Psychometric testing in Norwegian long term and home care contexts. BMC Nurs. 2015; 14: 59. doi: 10.1186/s12912-015-0109-3. PMID: 26578847, PMCID: PMC4647290.

24) Boyle M, Kenney C, Butcher R .The development of the Australian basic intensive care knowledge test. Australian Critical Care. 1995; 8(3): 10-16. doi: 10.1016/S1036-7314(95)70284-3. PMID: 8714890.

25) Fisher MJ, Marshall AP, Kendrick TS. Competency standards for critical care nurses: do they measure up? Aust J Adv Nurs. 2005; 22(4): 32-9. PMID: 16496834.

26) Toth J. The Basic Knowledge Assessment Tool. BKAT. 2012. Available from: http://www.bkat-toth.org.

27) Lo Biondo-Wood G, Haber J. Nursing research: Methods and critical appraisal for evidence-based practice. 2005.

28) Wild D, Grove A, Martin M, Eremenco S, McElroy S, Verjee - Lorenz A, et al. Principles of good practice for the translation and cultural adaptation process for patient - reported outcomes (PRO) measures: report of the ISPOR Task Force for Translation and Cultural Adaptation. Value Health. 2005; 8 (2): 94-104. doi: 10.1111/j.1524-4733.2005.04054.x. PMID: 15804318.

29) Polit D, Beck CT, Owen S. Focus on Research Methods Is the CVI an Acceptable Indicator of Content Validity? Appraisal and Recommendations. Res Nurs Health. 2007; 30: 459-67. doi: 10.1002/nur.20199. PMID: 17654487.

30) Wynd CA, Schmidt B, Schaefer MA. Two Quantitative Approaches for Estimating Content Validity. West J Nurs Res. 2003; 25(5): 508-18. doi: 10.1177/0193945903252998. PMID: 12955968.

31) Polit D, Beck CT. The Content Validity Index: Are You Sure You Know What's Being Reported? Critique and Recommendations. Res Nurs Health. 2006; 29: 489-97. doi: 10.1002/nur.20147. PMID: 16977646.

32) Burns N. Grove SK. The Practice of Nursing Research. Conduct, Critique and Utilization. 5th ed. WB Philadelphia: Saunders Company; 2005.

33) Munro BH. Statistical methods for health care research: Lippincott Williams \& Wilkins; 2005.

34) Rode N. Translation of measurement instruments and their reliability: An example of job-related affective well-being scale. Metodoloski zvezki. 2005; 2(1): 15-26.

35) Schreiber JB, Nora A, Stage FK, Barlow EA, King J. Reporting structural equation modeling and confirmatory factor analysis results: A review. The Journal of Educational Research. 2006; 99(6): 323-38. doi: 10.3200/JOER.99.6.323-338.

36) Plucker JA. Exploratory and confirmatory factor analysis in gifted education: Examples with self-concept data. Journal for the Education of the Gifted. 2003; 27(1): 20-35. doi: 10.1177/016235320302700103.

37) Lakanmaa RL, Suominen T, Ritmala-Castren M, Vahlberg T, Leino-Kilpi H. Basic Competence of Intensive Care Unit Nurses: Cross-Sectional Survey Study. Biomed Res Int. 2015; 2015: 536724. doi: 10.1155/2015/536724. PMID: 26557676, PMCID: PMC4628747. 